\title{
Luces y sombras en la enseñanza del Diseño. Una reflexión sobre su transformación en saber universitario
}

\section{Ledesma, María}

Resumen: Se propone poner en evidencias las capas aluvionales que construyeron y concepciones del mundo que sostienen las prácticas pedagógicas de las carreras de diseño en el marco de las universidades explicitando sus tensiones a la luz de un estudio genealógico que sirva como fundamento para considerar las condiciones del dispositivo de enseñanza para enfrentar las problemáticas de la civilización tecnodigital en un mundo políticamente globalizado pero internamente desgarrado.

Palabras claves: Genealogía Universidad - Disciplina - Civilización Tecnodigital.

$\left(^{*}\right)$ Dra. en Diseño. Prof. de

\section{Cuadernos del Centro de Estudios de Diseño y Comunicación № 67}

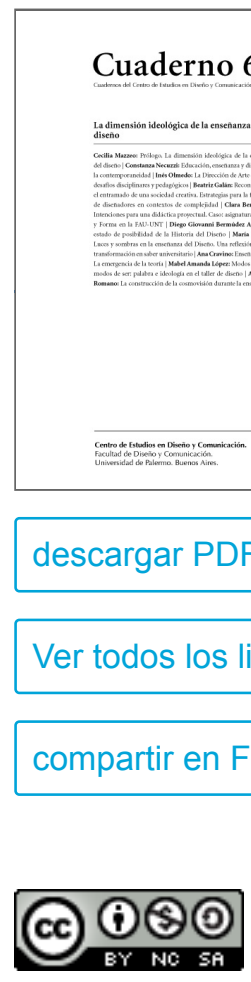

Esta obra está bajo una Licencia Creative Commons Atribución-NoComercialCompartirlgual 4.0 Internacional

Comunicación en la Carrera de Diseño Gráfico en la FADU UBA. Investigadora en Teoría del Diseño.

\section{Casos}

El Pabellón de Seda se alza en una sala del MIT. Seis mil quinientos gusanos tejen diligentemente guiados por su instinto ciego sobre una estructura de acero tejida por un robot (Ver Figura 1). Es una impresionante construcción que combina la investigación cientí- fica, el diseño digital y la construcción biomimética en la búsqueda de nuevas formas y nuevos materiales. En Concordia University -Canadá-, Tagny Duff y su equipo, desarrollan Cryobook Archives un proyecto centrado en la creación de una instalación interactiva que produce y exhibe cryobooks de piel humana y de cerdo, a través de procesos biotecnológicos y de vida sintética, incluyendo virus biológicos clonados, genéticamente modificados con un gen de medusa (Ver Figura 2)1 .

En Argentina, en la edición 2016 del tradicional Encuentro Internacional de Diseño TRIMARCHI2 uno de los conferencistas principales es el cyborg británico Neil Harbisson autor de una sinestésica teoría de color y sonido probada en sus capacidades extrahumanas. Lo acompaña Moon Rivas una reconocida activista cyborg dotada 
con percepciones extrasensoriales. Mientras tanto, en las carreras de diseño la reflexión sobre las tecnologías y nuevos materiales está prácticamente ausente de los planes de estudio, de los centros de investigación y de los intercambios académicos. Consideraré esa ausencia como 'un punto ciego', un espacio donde no llega la luz, en la enseñanza del diseño como pretexto para desarrollar una reflexión sobre la oscilación de luces y sombras en lo que se enseña y lo que no se enseña.

\section{Claves de lectura}

La combinación de la Nano, Bio y Cogno tecnologías con la TICS nos han sumido en una dinámica de cambios, cada vez más acelerada que ha puesto en suspenso los modos clásicos de estar en el mundo, haciendo emerger nuevas modalidades, nuevas prácticas de muy diverso tipo que coexisten y compiten entre sí.

Los casos detallados más arriba son apenas ejemplos del fuerte impacto que ha generado en el campo del proyecto la emergencia de estas realidades y prácticas dando lugar a nuevas denominaciones, apenas balbuceantes, pero que circulan por los pasillos de las escuelas de diseño. No es extraño escuchar discursos que aluden a una crisis de la proyectualidad (los modos habituales de proyectar han entrado en contradicción con las exigencias de la realidad); a una cierta 'post proyectualidad' (nuevos ejes de ya no pasan la proyectación, por lo menos tal como se la entendió desde del Moderno) o a un 'diseño expandido', expresión que alude a una suerte de expansión de los límites de la proyectación, más allá de los objetos, más cerca de los procesos.

Estos términos aún no tienen la categoría de conceptos téoricos; son apenas nuevas maneras de intentar acercarse y de nombrar lo que sucede en el nuevo escenario. Constituyen una constelación de indicios que guían, obstinadamente, la mirada hacia esa nueva realidad que aún no alcanzamos a comprender en su totalidad.

Baste observar el siguiente esquema3 (Ver Figura 3) en el que se grafican los diversos tipos de 'pararealidades' existentes para inferir que el pasaje de una realidad a otra, está más cerca del Design Fiction4 que de la ciencia ficción.

Se ha dicho que estamos educando para profesiones que aún no existen. Con esta expresión se alude al cambio en el centro de gravedad de los modos de organización del conocimiento y a su acelerada obsolescia que exceden con creces la cuestión -si se quiere hasta banal- respecto a pensar en cómo incorporar las tecnologías a la educación para favorecer los ambientes de aprendizaje. De lo que se trata es de pensar (de volver a pensar) el lugar que estas tecnologías tienen hoy en el mundo en que vivimos. De pensarlas por fuera de alientos exultantes pero también por fuera de los temores de una invasión maquínica. Es un hecho que, en contraposición a la pluralidad de las sociedades del pasado, la actual con el desarrollo de tecnociencia intenta transferir las capacidades humanas a las máquinas o a la inversa, multiplicar las capacidades humanas sumándoles las de las máquinas. El Pabellón de Seda, las pieles mutadas y conservadas a temperaturas extremas o la percepción extrasensorial de los cyborgs son ejemplos de la fusión biomaquínica soñada desde el siglo XVIII, casi acariciada hoy. Aunque suene obvio, es preciso subrayar otro rasgo común entre ellos, los tres pertenecen al ámbito del diseño: arquitectónico, el primero; de objetos editoriales el segundo; de percepción y color, el tercero y como tales, golpean a la puerta de los talleres de enseñanza, se incluyen en los 
conferenciantes de los encuentros de diseño o aparecen duplicados en los planteos de tesis de nuestros estudiantes que, por ejemplo, buscan usar las algas vivas para producir nuevos materiales.

La novedad nos asombra pero, en la medida en que estas estrategias emergentes avanzan, en la medida en que tecnocultura se desarrolla hacia situaciones apenas imaginables, aumenta la perspectiva con que podemos observar el pasado cercano. Hace treinta años en el momento de la eclosión de las carreras de Diseño, la perspectiva digital recién comenzaba a vislumbrarse y desde punto de vista, casi podemos decir que estas carreras nacieron a la vida universitaria alumbradas por el paradigma 'muriente' más que por el paradigma naciente. Esta marca de nacimiento no será sin consecuencias.

El diseño argentino -tal como lo conocemos- se acuna en los tempranos sesenta y en los dionísiacos setenta (teniendo en cuenta que los setenta murieron en Argentina en 1976). Hubo entonces, un conjunto de voces de distintas procedencias institucionales y disciplinares, con distintas filiaciones epistémicas, con variadas procedencias sociales que contribuyeron a abonar el terreno de lo que luego sería -casi diez años después-el programa universitario del diseño; algunas se encontraron, dialogaron y hasta tuvieron proyectos comunes; otras, giraron el orden de sus preocupaciones y se embarcaron en proyectos de otro orden; otras, nunca se encontraron y se eclipsaron sin dejar documentaciones fehacientes pero todas ellas contribuyeron con su obra, sus producciones, sus actividades de enseñanza a instalar el pensamiento de diseño en Argentina.

Hoy, apenas unos años después, nos encontramos a suficiente distancia de aquellos inicios como para captar mejor los rasgos diferenciales de aquel conjunto, rasgos que representaban fuertes concepciones ideológicas respecto de las concepciones del saber o el lugar de la práctica y la técnica en relación a la teoría.

Desde tal punto de partida, el artículo propone en primera instancia volver a mirar el proceso de formación de nuestros actuales programas de enseñanza para poner en evidencia cómo en lo enseñado y en lo no enseñado respecto del diseño, alientan cuestiones que tienen efectos sobre el desarrollo del diseño mismo; se trata de una reflexión en un marco históricamente extendido en el que se pueden encontrar indicios, hechos, documentos que proporcionen una explicación sobre las lógicas actuales.

Me alienta la convicción que un sinceramiento respecto de las diversas concepciones que subyacen a la enseñanza del diseño y el proyecto puede contribuir a repensar los modos de enseñanza en línea con el diagrama de fuerzas que se da nuestra contemporaneidad.

Así, el análisis sobre las distintas concepciones y jerarquías del saber que coexisten en la enseñanza del diseño, no tiene un interés descriptivo sino propositivo. En efecto, si el modelo actual tiene fisuras que lo alejan de la comprensión de los nuevos sucesos que anidan en la propia disciplina, sólo se lo puede trascender con un énfasis propositivo que se esbozará en la parte final del artículo.

No se me escapa que los ejemplos presentados pueden parecer ajenos a nuestro entorno. Sin embargo, -como ya se habrá comprendido- los he elegido ex profeso porque son ejemplos que llevan al máximo grado la alianza de la biología con la computabilidad matemática para la producción de objetos diseñados. Como se dijo más arriba, los tres son ejemplos de diseño: nuevas telas y nuevos materiales, nuevas experiencias sensoriales, extensión de los sentidos, sinestesia. Dichas así, las palabras nos resultan familiares. Podemos explicar cada una de ellas. Sin embargo, esas palabras no refieren a las mismas realidades: 
Hablar y escribir en la época de los códigos digitales y las transcripciones genéticas ha perdido por completo el sentido que le era familiar; las tipografías tecnológicas se están desarrollando en un sentido que ya no es el de la transmisión, y que ha dejado de evocar la simplicidad doméstica, y los efectos de una conciliación con lo externo. Ensanchan más bien, al contrario, el perímetro de lo externo y lo radicalmente inadmisible. (Sloterdijk, 2011, p. 136)

Ese perímetro de inadmisibilidad es también el de la posibilidad. En él quiero centrarme para enfatizar acerca de una carencia en los programas de enseñanza universitarios de diseño: la reflexión sobre la técnica, entendida no de manera instrumental sino como matriz tecnosocial en la que se da la producción de diseño. Y ese punto ciego, servirá también de apoyo para mostrar los conos de luz que sí iluminan otras áreas de la enseñanza del diseño confiriéndole un movimiento que la impulsa en dirección de otras áreas de la cultura5 .

\section{La escena universitaria}

En el corto lapso que va desde la década del 60 a la década del 90 del siglo pasado, en Argentina, el diseño experimentó un desarrollo y una transformación tan considerables que modificarían su perfil profesional y pedagógico de manera radical. Hasta entonces, se encontraba disperso en una serie de prácticas de muy diferente tenor y raigambre episté- mica. Quienes desarrollaban esas prácticas provenían de campos heterogéneos: ingenieros y arquitectos diseñaban automóviles, motocicletas o mobiliario; artistas plásticos y arquitectos ideaban publicidades gráficas, tipógrafos, linotipistas o armadores diseñaban ediciones impresas y letristas componían carteles en la vía pública, mientras que modistas artesanas confeccionaban prendas de vestir.

Vale la pena remarcar que la práctica del diseño vinculada al desarrollo de la producción, la circulación de mercancías y la transmisión y producción de valores culturales delimitó primero un lugar profesional y sólo más tarde, un espacio académico. En efecto, en una etapa inicial el reconocimiento del diseño como factor de desarrollo económico propició el nacimiento de las primeras organizaciones profesionales que aparecen en la Argentina en 1948, siguiendo la tendencia inaugurada en la década del 30 en EEUU y Europa.

Años después estos agrupamientos obtuvieron su legitimación en el concierto de los campos escolásticos al entrar dentro de la enseñanza universitaria o superior: en 1958 se crea la carrera de Diseño en la Universidad Nacional de Cuyo y cinco años después, en 1963 las carreras de Diseño en Comunicación Visual y Diseño Industrial en La Plata.

Ambas universidades incluyeron las nacientes carreras en las facultades de Arte pero tomaron decisiones diferentes respecto a su conformación. En la primera, el Diseño constituirá un todo sin especializaciones mientras que en La Plata se las dividió en dos ramas:

Diseño Industrial y Diseño de Comunicación Visual; sin embargo, ambas organizarán sus planes de estudio siguiendo el modelo cientificista de Ulm (Ledesma, 1997). A pesar pertenecer a facultades de arte, las tres carreras mantenían vínculos estrechos con la arquitectura, tanto por sus fundadores, profesores y programas como por su adscripción al campo proyectual -en La Plata- o a la teoría del Diseño -en Mendoza-. 
Habrían de pasar más de veinte años para que la experiencia iniciada en 1958 se generalizara. Las luchas revolucionarias y el hiato de la dictadura producido entre 1976 y 1983 suspendieron el proceso de institucionalización académica del diseño. Pero con la creación de las carreras de Diseño Gráfico y Diseño Industrial en la Facultad de Arquitectura y Urbanismo de la Universidad de Buenos Aires (también bajo el modelo de Ulm) se produjo una verdadera explosión de carreras de diseño a lo largo y a lo ancho del país. La entrada de los diseños en la universidad puso en evidencia los conflictos propios de su formación heterogénea: las relaciones entre profesionales e investigadores de diferentes orígenes no fueron sencillas dando lugar a acciones, muchas veces complementarias pero muchas otras, contradictorias y opuestas de diferentes maneras.

Esta presentación cronológica ayuda a ordenar los hechos pero el trabajo que me propongo es de orden genealógico; se ocupa por lo tanto, de los azares de los comienzos antes que de la certeza de los orígenes (Foucualt, 1992). Se trata de buscar la procedencia, los lugares desde donde se viene, pensando que el pasado alienta en el presente pero detrás de numerosos velos. Sin quitarle importancia a la instancia de creación de las carreras se busca desbrozar el hito fundador, sin hacer una historia de héroes o heroínas, sino al contrario, poniendo en evidencia, la heterogeneiad del origen.

Dado que la identificación de la procedencia, "agita lo que permanecía inmóvil, fragmenta lo que se pensaba unido" (Foucault, 1992), esta genealogía se dirige a mostrar el ensamblaje que compone esa unidad que llamamos 'enseñanza del diseño' no para recomponer esa supuesta unidad sino para mostrar a los distintos actores, manteniendo la dispersión que le es propia. La idea del origen, al consagrar un punto de inicio (un ademán sacralizador, un hecho extraordinario, la aparición de una obra) desprecia un sinnúmero de elementos que de manera subterránea confluyen en la urdimbre que organiza los hechos del presente. La genealogía, al contrario, busca la "pluralidad de cosas que hay en una" (Foucault, 1992), identificando las voces que no forman un coro armónico sino que, al contrario, mantienen entre sí relaciones de vasallaje y dominación. Para el método genealógico los momentos de emergencia son aquellos en los que el conflicto se explicita permitiendo vislumbrar la heterogeneidad; en estos términos, la decisión de crear las carreras de diseño conformó el episodio que en esa época hizo visibles una serie de servilismos en la historia del saber y del poder que, como sabemos, van de la mano.

Con la idea de mostrar esa urdimbre, desechando la idea de una unidad, convocaré a los participantes de una escena que hace más de treinta años se daba en nuestras casas de estudio. Describiré la escena con palabras muy parecidas a las que usara con Mónica Pujol en un viejo artículo (Ledesma y ot, 2011) tomando como ejemplo las reuniones o los encuentros en la sala de profesores de los enseñantes de las nuevas disciplinas académicas. Los personajes principales eran cuatro: el profesional idóneo venido de la gráfica o del mundo de la costura , el arquitecto devenido diseñador, el semiólogo devenido comunicador y el profesional idóneo venido del arte.

Cada uno de los protagonistas que se acaban de convocar representa una visión de los saberes en pugna: el técnico, el teórico académico, el académico proyectual, el manual artesanal. Esa procedencia heterogénea muestra la disociación en la constitución de estas disciplinas que hoy llamamos proyectuales.

Esta particular confluencia se tradujo en la aparición, en torno a la universidad, de una escena de discursos fundacionales en la que se cruzaban -muchas veces con aspereza- voces provenientes de la arquitectura, del 
diseño como práctica idónea, del arte, de la sociología, la comunicación, del cine.

En cada facultad argentina la escena se montó de diferentes maneras, con un denominador común: las relaciones entre profesionales e investigadores de distintas procedencias generó líneas de fuerza con diferentes impulsos, acciones y núcleos que, en su heterogeneidad, se complementaban, contradecían y oponían de maneras diversas. Ejemplos ilustrativos son lo sucedido al interior de la carrera de Diseño Gráfico o en la Diseño de Indumentaria y Textil en la FADU-UBA.

En la primera, los diseñadores 'idóneos', alejados de la Academia rechazaban a los profesionales llegados de otros campos quienes, a su vez, proponían las lógicas en las que estaban formados, al tiempo que las ideas que definían al Diseño Gráfico como arte eran tan fuertes como aquellas que lo definían como comunicación; el paradigma administrativo de la comunicación se enfrentaba, a su vez, con posiciones provenientes de los paradigmas semiótico y crítico mientras los técnicos insistían en caracterizar al diseño como espacio de mediación entre clientes y receptores. Así (y la anécdota es real) en una mesa redonda alguien podía empezar su intervención diciendo: 'Sobre gustos no hay nada escrito' y recibir de golpe la información que sobre el gusto se han escrito volúmenes y volúmenes. Entre el saber del idóneo y en el saber del académico se evidenciaban las fisuras de la inestabilidad del origen. La riqueza y virulencia de las discusiones nutrió el campo, delineó posiciones, dividió espacios y estableció zonas de mayor o menor prestigio institucional y/o profesional que tuvo manifestaciones tanto al interior de la propia universidad como en el campo del diseño en general.

En Indumentaria y Textil, la escena fue aún más virulenta: las modistas (nombre despectivo con que se designó a quienes no tenían título universitario) tuvieron que lidiar con un doble anatema: el de no pertenecer a la Academia y el de ser mujer. Los maniquíes que aparecían en manos de los estudiantes causaban escándalo como si una horda salida del mundo laboral hubiera irrumpido en un espacio sagrado. El espacio del saber aparecía ultrajado por el mundo de la práctica.

A pesar de la fuerza de estas escenas, con el tiempo ha sido silenciada. Aquello que aparecía desunido, hoy aparece unido bajo la denominación de 'disciplinas proyectuales'. Pero la unidad es sólo aparente: esas posiciones se fueron adaptando, adormeciendo o fortaleciendo pero sea cual fuere su transformación (su dominación o servilismo) continúan latiendo en nuestras adhesiones y nuestros desprecios.

Uno de los objetivos de este artículo es mostrar las capas aluvionales que las construyeron, las concepciones del mundo que las sostienen, explicitando sus tensiones a la luz de una genealogía del saber que sirva como fundamento para considerar cuán preparados estamos para enfrentar las problemáticas de la civilización tecnodigital en un mundo políticamente globalizado pero internamente desgarrado.

De vasallos, señores y configuraciones disciplinares

La variedad de modos de saber que se encuentran en una sociedad (muchas veces complementarios, muchas veces en pugna, muchas veces vecinos, ignorándose entre sí) se organizan según un complejo sistema de legitimaciones y jerarquías: desde los sistemas científicos hasta los de conocimientos mágicos, desde los saberes sagrados hasta los conocimientos prácticos, cada uno se organiza en esferas autónomas con diferentes modos de obtener legitimidad y jerarquizadas entre sí. Cada esfera, a su vez, contempla jerarquías internas en relación al grado de saber de sus miembros: en el sistema del saber mágico, un chamán ocupa una jerarquía 
mayor respecto de los participantes del rito de la misma manera que un profesor emérito ocupa la suya en relación al que se inicia. (Beillarot, 1989) Así se establece en cada formación cultural y contexto histórico un doble sistema de subordinación: ciertos saberes son más valiosos que otros y, consecuencia inmediata, se establece un dominio por parte de quienes poseen el saber que está en la cúspide de la pirámide jerárquica, respecto de quienes no lo poseen.

Es sabido que la cultura occidental ha jerarquizado la razón sobre los sentidos; el sujeto sobre los objetos, con un resultado bastante categórico: el privilegio del espíritu sobre la carne, de la reflexión argumentativa y demostrativa sobre las otras capacidades humanas, el privilegio de la vista y el oído en desmedro de los demás sentidos, el privilegio de la teoría por sobre la práctica y la preferencia de lo bello sobre lo útil.

Un largo proceso de siglos con diversos puntos de emergencia ha conducido a la situación en la que el hombre ilustrado se siente superior al técnico, el artista al constructor y el médico a la enfermera. De manera más general, el triunfo de la expresión Homo Sapiens acuñada por Lineo en los inicios de la modernidad racional por sobre la más antigua, el Homo Faber, es un indicador del resultado de ese conflicto entre la especulación y la acción y de ninguna manera es un dato menor para las carreras de diseño, el carácter de privilegiado del pensador por sobre el productor.

La conformación que acabamos de plantear reconoce diversos momentos de emergencia que Foucault describe como espacios de verdadera confrontación cuyo resultado es el sometimiento, la dominación de los artesanos, de los técnicos, de los constructores, de los que se ensucian las manos con el trabajo.

¿No es posible reconocer en esos desplazados algunos de los personajes que confluían en la escena del diseño? ¿No se adivina el técnico, no se perfila el artesano?

Volvamos a mirar nuestra escena. Ocurre -como se ha dicho- en el momento de emergencia de un conocimiento a causa de un resultado histórico determinado por condiciones que han hecho posible esa irrupción. El diseño 'ha saltado' de la esfera de los saberes ordinarios a la esfera de los saberes legitimados por la institución universitaria. Es cierto que desde Morris y la Bauhaus6, el diseño ya no estaba vinculado exclusivamente al universo de las artes aplicadas y los oficios pero, hasta el momento, las instituciones educativas en las que se enseñaba, no tenían el prestigio de la Universidad.

Ese salto de esfera, supuso una nueva posición en el sistema general de organización de los saberes y dado que todo conocimiento siempre es una estrategia en la que se está situado, hubo posiciones de "servilismo" (Foucault, 1992) que respondían a las jerarquías atribuidas a los distintos campos del saber. No cabía duda de que serían los letrados quienes liderarían el proceso de inclusión en la nueva esfera. Según la procedencia de estos líderes letrados, las carreras de Diseño se alojaron alternativamente en facultades de Arquitectura, Arte o escuelas de Ciencias de la Comunicación produciendo una situación pocas veces tenida en cuenta: que el diseño haya entrado a la universidad en esas facultades no habla sólo del carácter epistémico del diseño sino también de la configuración socioinstitucional de la enseñanza universitaria.

Las disciplinas constituyen formas de organización del conocimiento que facilitan el abordaje de los contenidos científicos, filosóficos o técnico tecnológicas tanto para la investigación como para la enseñanza. Se definen porque constituyen campos de estudio para una comunidad que desarrolla sus actividades en escuelas 
superiores o universidades, que tienen órganos de difusión y discusión de sus ideas donde se exponen los resultados de los procesos investigativos o las preguntas y problemas que preocupan a la comunidad académica e intelectual a la que pertenecen los investigadores. (Beillarot, 1989)

A esta definición clásica -que reconoce tanto la existencia de subdisciplinas como la aparición de distintos agrupamientos disciplinares a lo largo de la historia- corresponde hacerle una pregunta: ¿cómo se organiza, cómo se decide cada agrupamiento disciplinar?

Hay, por supuesto, una tradición histórica; hay un cierto estatuto ontológico que acerca ciertos saberes a otros que intervienen en la separación imaginaria de esos territorios llamados 'disciplinas' que se imponen imaginariamente a nuestro hábito académico con tanta pregnancia que se han naturalizado hasta que el punto que pareciera que ellas refieren de modo un modo transparente a su objeto de estudio.

Lo que queda oculto en toda propuesta académica es que la organización disciplinar responde a criterios de muy distinto orden que incluyen tanto cuestiones epistémicas e históricas como posiciones socioinstitucionales que generan rupturas e inclusiones como resultado de procesos de disputa sobre las jerarquías. De hecho, la dimensión socioinstitucional corresponde a la inserción real y concreta de la actividad científica en la sociedad y se pone de manifiesto tanto a través de las instituciones tales como universidades o centros de investigación, como por las modalidades establecidas por los sistemas educativos que organizan carreras, áreas y materias. (Gianella, 2006)

¿Puede explicarse de otra manera que el ordenamiento disciplinar del Consejo Nacional de Investigaciones Científicas y Técnicas (CONICET) contemple una disciplina llamada Medicina junto a otra llamada Odontología? Que la salud del cuerpo y de la boca pertenezcan a ámbitos diferentes sólo puede ser consecuencia de criterios socioinstitucionales, alejados de criterios históricos o epistémicos. En el mismo orden, como señalamos más arriba, la inclusión del diseño en la universidad en facultades tan diferentes como Arquitectura, Arte, Comunicación o hasta en escuelas de Tecnología, no se debe sólo a su historia o a su episteme sino también y en gran medida a la configuración socioinstitucional de la enseñanza universitaria.

No obstante la cantidad de facultades que albergan carreras de diseño, son las de Arquitectura las que han dictado el ritmo de las lógicas del diseño. La influencia de la escuela de Ulm ha sido decisiva para la conformación de los programas de estudio de las carreras de diseño. Esto no constituye una excepción en tanto la Argentina siempre ha seguido las corrientes hegemónicas occidentales en la estructuración de sus planes de estudio; en esa línea, los arquitectos/diseñadores locales también siguieron la transformación que experimentó Ulm hacia 1958, cuando declaró obsoleto el modelo de Bauhaus, y potenció las áreas científicas en el plan de estudios. Sin embargo, a pesar de este predominio, las referencias al arte se mantuvieron en la superficie durante muchos años: el énfasis que muchos diseñadores ponían (y aún hoy siguen haciéndolo) en decir a los cuatro vientos que 'el diseño no es arte', muestra por la negativa la vigencia de aquellas posiciones.

Este excurso preliminar tiene como objetivo reconocer -a la luz de nuestras concepciones del saber universitario- qué aspectos juegan en la enseñanza del diseño, haciendo hincapié en un punto tan sencillo como ciego: aquello que se elige para enseñar deja de lado aspectos que no son enseñados. 
Si se consideran las condiciones de producción del conocimiento universitario en su aspecto más general, se puede afirmar que en él se privilegian las lógicas del saber especulativo demostrativo por sobre las lógicas del hacer. En Argentina, como en la mayoría de las universidades, las reglas de producción del conocimiento, las formas en que se lo produce, los modos de validación y los mecanismos de recompensa son dictadas por las facultades y centros de producción del conocimiento en las que predomina la lógica investigativoacadémica. Sin embargo, dado que la enseñanza del diseño pivotea entre las lógicas profesionales o técnico instrumentales, sus carreras no son reconocidas ni evaluados desde criterios propios de su campo sino que se las somete a los modelos y reglas del campo científico tal como es entendido desde las lógicas de las Ciencias Exactas o Sociales. Esta situación de vasallaje genera dos respuestas opuestas: hay quienes, en consonancia con desarrollos similares en el mundo, se han dado a la tarea de posicionarse en el sistema académico lo que implica completar la tarea de definir las particularidades del diseño como conocimiento o, dicho en otras palabras, plantear su epistemología y su condición relativa al desarrollo del conocimiento en general y hay quienes, se abroquelan en posiciones que rechazan los intentos de desarrollo teórico, despreciando las lógicas rectoras de aquel pensamiento especulativo. La escasez de las publicaciones académicas, la baja densidad de las investigaciones son algunos indicadores de la fuerza que tiene la segunda respuesta en relación a la primera.

La enseñanza del diseño no sólo reclama reconocimiento al interior de la universidad, sino también en el seno de las facultades que lo hicieron nacer y le dieron cabida como disciplina universitaria. En su libro sobre la historia del Diseño Latinoamericano, Bonsiepe (2008) aboga por una posición de autonomía respecto de la arquitectura. La discusión es profunda pero puede sintetizarse en dos opiniones: la de quienes se orientan a fortalecer el vínculo del diseño con todas las áreas del proyecto proponiendo al proyecto como metáfora de la episteme de la época y quienes reclaman la autonomía del diseño tanto de las escuelas de arquitectura como las de arte.

Por su parte, dado las disciplinas que organizan el conocimiento universitario mantienen ocultas las cuestiones socioinstitucionales que intervienen en su definición, presentándose en una relación directa con el objeto al que se refieren, pareciera que el diseño es algo diferente en cada una de sus manifestaciones. En la actualidad, en Argentina hay más de cuarenta programas para la enseñanza de diseño en las carreras de grado universitarias tanto en instituciones públicas como privadas y un número equivalente de instituciones terciarias (se trata de centros de enseñanza de nivel superior sin rango de universidad). Las variantes oscilan como Diseño Industrial, Diseño del Objeto, Diseño de Paisaje, Diseño Gráfico o de Comunicación Visual, Diseño Multimedial y Diseño de Indumentaria, Diseño Textil o Diseño de Modas, adscripciones nominales que alientan la idea que ese recorte es la disciplina y que esa disciplina es el objeto, conformando cotos cerrados en lugar de un espacio general que posibilite los trasvasamientos.

Este sistema de pendencias y jerarquías delinea un sistema triádico de cuestiones ignoradas, o por lo menos no demasiado pensadas que configura una matriz que engloba la enseñanza del diseño:

1.

Por un lado, conviven en diversas facultades carreras de diseño con pocos puntos de contacto entre sí. 
En la FADU UBA con un máximo grado de dispersión se dictan siete carreras de Diseño: Arquitectura, Diseño Gráfico, Industrial, de Indumentaria y Textil, de Imagen y Sonido y Licenciatura en Paisaje. Entre esas carreras, unas pocas asignaturas se ofrecen para todos los estudiantes. En la práctica, (y de manera contradictoria a los planteos ulmianos de los que surgió) la malla curricular no está integrada sino que las materias funcionan como mosaicos independientes sin más relación que las que plantean los docentes de manera espontánea. Sólo las carreras más nuevas o las reformulaciones que se han podido hacer en algunas universidades nacionales muestran alguna renovación tendientes a repensar el diseño más allá de la realización del producto, incluido en los nuevos desafíos de la complejidad contemporánea haciendo hincapié en un pensamiento global de diseño orientado a la gestión de procesos más que a la mera realización de productos aislados

2.

En las facultades donde se dicta Arquitectura, se repite la jerarquización de las carreras de diseño según una pauta que considera a arquitectura en la cúspide respeto de las otras. Esto se observa no sólo en la adjudicación de los recursos materiales sino también por la reacción de los diseñadores frente a los arquitectos.

3.

Por último, se observa al interior de cada una, la supeditación de la ideación a los saberes técnicos. Hay un saber del arquitecto vinculado a la proyectación y esta a la ideación. Tanto por la distribución horaria como por los imaginarios que circulan por las escuelas de diseño, la valoración de profesores y alumnos está claramente puesta en el taller especialmente 'Diseño' considerada 'materia troncal' en todas las carreras. Hay un saber técnico instrumental desvalorizado y ajeno a las lógicas de la universidad

Este esquema no da cuenta de la variedad de posiciones que forman la urdimbre pero sí ordena las concepciones que permiten volver a los ejemplos que se inició este artículo.

Respecto de la técnica

Todo plan de estudios es un instrumento educativo en el que confluyen concepciones respecto de la sociedad y su dinámica con una compleja amalgama de representaciones respecto de los procesos de producción, transmisión, reproducción, regulación, legitimación y acción de los saberes en dicha dinámica social.

Esta complejidad pone en juego principios de orden político, social, cultural junto a principios epistémicos, pedagógicos y didácticos sobre los que se organiza el plan tanto en sus objetivos como en sus contenidos, en los perfiles que busca y en las prácticas que promueve. El desarrollo anterior ha buscado mostrar el revés de la trama de la escena universitaria con el objetivo de poner en evidencia el ensamblaje oculto /olvidado/ que sostiene nuestras carreras respecto a las representaciones de cómo se produce, reproduce, legitima y actúa el saber universitario en relación a las disciplinas del diseño y en función de ello, identificar los puntos de tensión, las posiciones en pugna, las dominancias. El análisis ha puesto de manifiesto que la entrada del diseño a la universidad argentina ha contribuido a su consolidación, su expansión y su desarrollo pero a condición de mantener ciertos puntos ciegos, ciertos puntos de no saber o por lo menos de descuido para la reflexión.

La técnica es uno de ellos. El escaso espacio que se ofrece en los planes y programas para las materias técnicas, la subordinación de estas al taller de diseño, la desjerarquización ante las llamadas materias 'teóricas', 
orientan para descubrir ese olvido o negligencia. Al observar esta desvalorización, no resulta para nada banal el hecho que el diseño (que durante siglos se mantuvo del lado de la técnica) haya ingresado al mundo universitario de la mano de la arquitectura y el arte7 porque en ambos campos ha prevalecido un régimen valorativo que ha generado un prejuicio inútil respecto de la técnica, prejuicio resultante de la larga y propia historia de pasaje del taller artesanal al taller de Beaux Arts y de allí al Taller de Arquitectura. En esa historia, las ideas de originalidad, de obra única, de realización individual constituyeron la punta de lanza que contribuyeron a marcar la diferencia con el trabajo colectivo del taller artesanal. La desvolorización de la técnica y del técnico está en relación con la separación entre lo útil -aquello necesario pero no especialmente valorado- y lo estético -aquel objeto extraordinario, único y bello- establecida por la modernidad (Simondon, 2008, p. 124). La pertenencia a esa régimen focalizó la atención en la contribución individual, en los conceptos de sensibilidad y inspiración y atenuó hasta casi hacerlas desaparecer todas las vinculaciones con el trabajo. En el caso de la Arquitectura, la etapa de estudio de la construcción de la obra, ocupa una fracción pequeñísima de los planes de estudio, centrados en la búsqueda de un diseñador proyectista, un diseñador de tablero, alejado del obrador y de los problemas que este acarrea.

Desde entonces y aún hoy, el hombre ilustrado considera que el técnico "tiene estrechez de miras" (Simondon, 2008, p. 36), el arquitecto cree que el ingeniero también, el diseñador no quiere ser llamado artista, pero tampoco técnico.

Mientras los objetos técnicos crecen y se desarrollan, subsiste la idea que esos objetos no contienen realidad humana. Sin embargo, hoy que el hombre se está planteando como hacedor de vida o hacedor de edificios empleando vida para construirlos, hoy que los gusanos tejen la tela del Palacio y el Cyborg diserta sobre teoría del color, debe estar frente a la pregunta de si lo que hace tiene que ver con él mismo. Porque (por si no nos damos cuenta) esos cyborgs, esos libros de piel humana nos golpean el hombro y obligan a que los miremos (ay, de nosotros si nos encogemos de hombros y pensamos que no tienen nada que ver con el diseño editorial o la enseñanza del color).

No puede pensarse el diseño por fuera de la técnica. $Y$ hablar de ella supone considerar tres ámbitos: las representaciones que se tienen sobre la propia cultura técnica -tanto los alientos mesiánicos como las extranjerías en las que se la colocan-; el manejo operacional de las técnicas y por último, los objetivos de los diseños, los valores y aspectos axiológicos de la cultura técnica. (Quintanilla, 1998)

Las escuelas de diseño parcializan y desarticulan esta tríada. La parcializan porque le otorgan poca relevancia en sus planes de estudio y la desarticulan, porque cuando consideran la técnica sólo lo hacen desde su aspecto instrumental.

III. Palabras finales

Decía al comienzo que el intento genealógico de mostrar los estratos que confluyen en la enseñanza del diseño en la dimensión de sus pugnas de poder, debía conducir a un punto ciego que debía servir de apoyo para mostrar los conos de luz que iluminan la enseñanza del diseño.

Caractericé este momento histórico como el del predominio de la civilización tecnodigital en un mundo políticamente globalizado pero internamente desgarrado. Las problemáticas de los desarrollos tecnocientíficos, 
son el resultado y al mismo tiempo uno de los motores propulsores de las políticas globales que no hacen más que profundizar la división del mundo a través de una brecha tecnológica que produce enormes acumulaciones junto a carencias inconmensurables. La velocidad creciente de los cambios tecnológicos tiene su contrapartida en la parálisis que afecta a la resolución de la pauperización de más de la mitad del mundo conocido. Sólo en ese contexto puede entenderse el nuevo paradigma científico tecnológico: como parte de una cultura desmembrada, desarticulada, en la que las mayores expresiones de desarrollo coexisten (a veces en el mismo hecho) con las más terribles imágenes de barbarie. Por lo tanto, si no queremos pecar de lo mismo que criticamos, tenemos que considerar la situación en la enseñanza en ese contexto general. Es sabido que las instituciones educativas tardan en incorporar los cambios de paradigmas pero también es sabido que la universidad -por su carácter de formador de pensamiento- refleja rápidamente las mutaciones. Esta paradoja (ser conservador/ser vanguardia) está presente en la enseñanza del diseño, que no se ha mantenido estático. Es cierto que no ha incluido una reflexión sobre la técnica (al contrario, a veces, peca por reclamar mayores saberes instrumentales) pero se ha mostrado sensible a otros aspectos de nuestra contemporaneidad, especialmente aquellos vinculados a la crítica de las abstracciones de la modernidad.

Son muchos los cambios que han aparecido en los últimos veinte años, de los cuales la irrupción de la digitalidad en los modos de proyectar no es menor. Sin embargo, hay un cambio mucho más profundo aunque menos reconocido en las escuelas de diseño. Se está mutando de un diseño centrado en el artefacto y en la forma o del análisis de las interacciones entre artefactos y usuarios a una concepción de diseño más amplia en la que se valora la inteligencia proyectual y su capacidad de incluirse en la trama social, en el territorio como dinamizador de sus espacios y su gente.

Para decirlo de manera más enfática, están cambiando algunos de las nociones que han sido eje de articulación académica de estas carreras. Al espacio abstracto de la modernidad, al territorio como tabla rasa, los nuevos movimientos de enseñanza -incipientes aún- lo definen como suma de sociabilidad, historia y paisaje, adjudicando un lugar central a las modificaciones que realizan las relaciones de producción; a la concepción estrecha de contexto, los nuevos movimientos la reemplazan por una consideración compleja de los tipos de contextos en los que está sumido un hecho de diseño; a la noción de diseñador/autor/ original se le opone la fuerza del diseño colaborativo.

Estos aspectos aún no han sido trasladados a los planes de estudio. Un análisis realizado hace unos años8 sobre cuarenta programas de la materia Taller de Diseño en diversas universidades argentinas y latinoamericanas, los dividió en tres grandes categorías: aquellos que apuntan a una proyectación técnica (afianzamiento de saberes técnicos instrumentales sobre el objeto o pieza), los que se orientan a considerar el espacio en el que los objetos y piezas se incluyen y finalmente, aquellos que consideran la proyectación y diseño como una actividad general constitutiva instalada en un contexto económico, social, político, regional, global. Para esta tercera concepción, es la disciplina y no las situaciones las que se miran desde el proyecto; sus programas sacan al diseño de su entorno restringido de la proyectación de productos o piezas para considerarlo como dimensión intelectual, cultural y simbólica que permite poner en acción elementos tecnológicos y reflexionar sobre ellos. Entre los cuarenta programas, sólo había dos con las características del último grupo: programas en los que el diseño se problematiza como tal, se expone en sus relaciones con la ciencia, la técnica y el arte y con la realidad socio-económico-política en la que se inserta. Sin embargo, más allá de los programas, esas concepciones son cada vez más frecuentes, cada vez más evidentes; la respuesta a su aparición hay que buscarla en el propio carácter del diseño que se retroalimenta a sí mismo. Aparecen en clases 
aisladas, en propuestas de transferencia, en algún proyecto de investigación. Es desde esos lugares desde donde llegan los discursos que mencionamos al comienzo, referidos a una cierta 'post proyectualidad' o a un 'diseño expandido'. Son discursos aún balbuceantes, desaprobados por la mayoría de la comunidad, pero son discursos presentes y con relativa consolidación. Y aunque parezca que no, están en línea con esta necesidad de pensar/repensar nuestro vínculo con la técnica porque se orientan a prescindir de la interpretación del mundo estructurada sobre la partición sujeto-objeto; partición obsoleta dado que "los hombres necesitan relacionarse entre ellos pero también con las máquinas... y aprender a tener una relación polivalente con el entorno". (Sloterdijk, 2011)

Notas

1. Debo este ejemplo a Claudia Kosak.

2. Trimarchi es un Encuentro Internacional de Diseño que comenzó a realizarse en el año 2000 en la ciudad de Mar del Plata a partir de la iniciativa privada de un grupo de diseñadores. No cuenta con avales institucionales sino con la adhesión de reconocidos diseñadores.

3. Agradezco a Miguel Grassi permitirme usar el esquema de su autoría que forma parte de su trabajo de tesis (en proceso) 'Uso de la Realidad Intervenida en las disciplinas proyectuales'.

4. El design fiction es un modo de producción caracterizado por la introducción de objetos ficticios pero tecnológicamente coherentes con la realidad en situaciones socioculturales en pos de analizar las interacciones que se generan. Esto se realiza a través de una narrativa ficticia, que generalmente, pero no siempre, toma la forma de película. Design Fiction es una de las tantas aproximaciones que aparecen para intentar dar respuesta a la compleja realidad en la que dominan las hibridaciones más que las purificaciones, usando la terminología de Bruno Latour (2007). Agradezco a Tomás Buccino el contacto con este concepto.

5. Quiero recordar dos textos que si bien responden a metodologías y concepciones diferentes a las que se plantean en el artículo son nodales para la comprensión de este proceso. Me refiero a La travesía de la Forma (2010) de Verónica de Valle y a Qué dice del diseño la enseñanza del diseño (2014) de Cecilia Mazzeo.

6. Dado que las actividades gráficas de edición o la producción de objetos (textiles, orfebrería, mecánicos) no tuvieron el prestigio del idear puro correspondiente a la arquitectura, en los vaivenes de la separación de las áreas del pensar y del hacer quedaron del lado de la artesanía o de las artes aplicadas con la consiguiente desvalorización social respecto de la arquitectura. Cuando Morris y luego la Bauhaus proclaman la unión de artistas y artesanos, expresan su rechazo a la arbitraria separación entre los que trabajan con las manos y los que trabajan con el concepto.

7. Es tal la fuerza que tiene la historia instituyente que en las explanaciones sobre el diseño Grafico por ejemplo, no se tienen en cuenta las producciones del Instituto Argentino de Artes Gráficas (IAAG), creado en 1907, que fue un referente de la cultura gráfica en Buenos Aires a principios del siglo XX (al crearse la carrera de Diseño Gráfico en la UBA, los profesores que se hicieron cargo de la materia Tecnología provenían de ese mítico instituto pionero en el quehacer gráfico. Con 116 años, bajo el nombre de Fundación Gutemberg continúa 
formando diseñadores argentinos) o las de arte como la Panamericana de Arte, muchos de cuyos profesores también dieron clases en la FADU UBA.

8. Trabajo inédito realizado para mi Tesis Doctoral (mimeo en Biblioteca de la FADU UBA).

Bibliografía

Beillerot, J. (1989). Los saberes y su naturaleza en Saber y relación con el saber. Buenos Aires: Paidós.

Bleeker, J. (2009). A short essay on design, science, fact and fiction. Near Future Laboratory. Disponible en: http://blog.nearfuturelaboratory.com/2009/03/17/design-fiction-a-shortessay-on-design-science-fact-and-fiction/ (visitado en agosto 2016)

Bonsiepe, G. y Fernández, M. (2008). Historia del Diseño Latinoamericano. San Pablo: Ed. Blücher.

Bordieu, P. (1999). Meditaciones pascalianas. Barcelona: Anagrama.

Concordia University -Canadá-, Tagny Duff. Disponible en: http://www.cjc-online.ca/ index.php/journal/article/viewFile/2532/2289

Devalle, V. (2009). La travesía de la forma. Buenos Aires: Paidós.

Foucault, M. (1970). La arquelogía del saber. México: Ediciones Siglo XXI. . (1992). Nietzche y la filosofía de la historia. En Microfísica del Poder. México: La Piqueta.

Gianella, A. (2006). Las disciplinas científicas y sus relaciones. En Revista Anales de la educación común, año 2 n 3. Dirección Gral de Educación de la Pcia. de Bs. As, Bs. As. pp. 74 a 83.

Latour, B. (2007). Nunca fuimos modernos. Buenos Aires: Siglo XXI Editores.

Ledesma, M. (1997). Un orden necesario. En Diseño y Comunicación Teoría y Enfoques Críticos con L. Arfuch y N. Chaves. Buenos Aires: Paidós.

Ledesma, M. (2005). Legitimidades y olvidos. Una contribución a la conceptualización del diseño. Tesis doctoral, mimeo, FADU, UBA, 2005.

. (2012). Prólogo a Lenguaje Gráfico TDE Más allá de la perspectiva de Claudio Guerri. Buenos Aires: Eudeba.

Ledesma, M.; Pujol, M. (2011). “De la Red Argentina de Carreras de Diseño (DISUR) al Plan Estratégico Nacional de Diseño (PENID)" en Diseño, Proyecto y Desarrollo Miradas del Período 2007-2010 en Argentina y Latinoamérica de Beatriz Galán compiladora. Wolkowicz Ediciones, Argentina

Mazzeo, C. (2014). ¿Qué dice del diseño la enseñanza del diseño? Buenos Aires: Infinito. MIT Media Lab. (MIT Media Lab's Mediated Matter Group). Disponible en: http://matter. media.mit.edu/environments/details/silk- 
pavillion

Quintanilla, M. (1998). “Técnica y cultura” en Teorema VII/3 Universidad de Oviedo, España pp. 49 a 69.

Sloterdijk, P. (2011). "El hombre operable. Presentación del concepto de homeotécnica” en Sin salvación. Tras las huellas de Heidegger. Madrid: Akal

Abstract: The article proposes to put in evidence the alluvial layers that constructed and conceptions of the world that support the pedagogical practices of the design careers within the framework of the universities explaining their tensions in the light of a genealogical study that serves as a basis to consider the conditions of the teaching device to face the problems of technodigital civilization in a politically globalized but internally torn world.

Key words: genealogy - university - discipline - civilization - technodigital.

Resumo: O trabalho propõe por em evidencia as capas que construíram e conceições do mundo que sustentam as práticas pedagógicas das carreiras de design no marco das universidades. Se procura explicitar suas tensões á luz de um estudo genealógico que sirva como fundamento para considerar as condições do dispositivo de ensino com o propósito de enfrentar as problemáticas da civilização tecno-digital num mundo politicamente globalizado, mas internamente rasgado.

Palavras chave: genealogia - universidade - disciplina - civilização - tecno-digital.

Luces y sombras en la enseñanza del Diseño. Una reflexión sobre su transformación en saber universitario fue publicado de la página 147 a página162 en Cuadernos del Centro de Estudios de Diseño y Comunicación № 67 